\title{
REDESAIN BANGUNAN BAGI DAN BANGUNAN SADAP DI DAERAH IRIGASI BENDUNG AIR KEMUMU KABUPATEN BENGKULU UTARA
}

\author{
Septi Kurnia Hayati Romah ${ }^{1)}$, Besperi ${ }^{2)}$, Gusta Gunawan ${ }^{3)}$ \\ ${ }^{122) 3)}$ Program Studi Teknik Sipil, Fakultas Teknik UNIB, Jl. W. R. Supratman, \\ Kandang Limun, Bengkulu 38371, Telp. (0736)344087 \\ email: septikurnia19@gmail.com
}

\begin{abstract}
Abstrak
Bendung Air Kemumu yang terletak di Desa Kemumu Kecamatan Arma Jaya, Kabupaten Bengkulu Utara merupakan salah satu bendung yang memiliki jaringan irigasi berupa saluran irigasi dan bangunan irigasi. Penelitian ini bertujuan untuk merencanakan dimensi saluran, bangunan bagi dan bangunan sadap berdasarkan debit kala ulang 5, 50, dan 100 tahun di kawasan irigasi Bendung Air Kemumu Kabupaten Bengkulu Utara. Pengamatan dan pengukuran secara langsung di lapangan mengenai dimensi serta permasalahan yang terdapat di lapangan. Metode penelitian yang dilakukan yaitu pengolahan data curah hujan dengan metode rerata aljabar. Data primer yang digunakan adalah kecepatan aliran di saluran dan dimensi saluran dan bangunan. Hasil perhitungan curah hujan rencana yang memenuhi syarat yaitu Metode Gumbel tipe 1. Perhitungan debit menggunakan metode rasional untuk berbagai kala ulang rencana. Hasil penelitian diperoleh perhitungan hidrolis saluran sekunder BW.1 dan tersier BS 2A berdasarkan debit saluran dilapangan didapat lebar dasar BW.1 sebesar 0,52 m dan BS 2A sebesar 0,35 m. Perhitungan desain saluran berdasarkan debit kala ulang untuk BW.1 dan BS $2 A$ dengan $Q_{5}, Q_{50}$, dan $Q_{100}$ berturut-turut yaitu didapat lebar dasar sebesar 2,14 $\mathrm{m} \mathrm{2,92} \mathrm{m} \mathrm{3,14} \mathrm{m} \mathrm{1,74} \mathrm{m} \mathrm{2,17} \mathrm{m,} \mathrm{dan} \mathrm{2,34} \mathrm{m.} \mathrm{Hasil} \mathrm{perhitungan} \mathrm{lebar} \mathrm{ambang} \mathrm{(b)} \mathrm{bangunan}$ bagi BW.1 dan sadap BS 2A berdasarkan debit saluran di lapangan yaitu BW.1 sebesar 0,44 m dan BS 2A sebesar 0,24 m. Perhitungan lebar ambang (b) berdasarkan debit kala ulang untuk BW.1 dan BS 2A dengan $Q_{5}, Q_{50}$ dan $Q_{100}$ berturut-turut yaitu sebesar 1,78 m, 2,44 m, 2,60 m, $1,50 \mathrm{~m}, 2,20 \mathrm{~m}$, dan $2,34 \mathrm{~m}$.
\end{abstract}

Kata kunci: bendung air kemumu, dimensi, debit kala ulang

\begin{abstract}
Air Keтити weir in Keтumu village subdistrict of Kecamatan Arma Jaya Bengkulu Utara Regency, is one of the weir which has irrigation canal and irrigation construction in its system. This research is aimed to plan the canal dimension, divider, and reservoir construction based on 5, 50, and 100 years periodic flow in Keтumu weir irrigation area of Bengkulu Utara. Observation and measurement were done directly in that area in order to find out the dimension and the problem. Research method that is used in this research is done by counting down the rainfall data by using algebra average method. The primary data are taken from the speed of water flow in canal, canal dimension, and construction dimension. The expected result of rainfall measurement that can complete pre-requirement is Gumbel method type 1. The measurement of the flow is using rational method for any types of periodic flow. The result of this research is finding the final hydrolysis measurement for the secondary BW.1 and tertiary $B S 2 A$ canal are $0,52 \mathrm{~m}$ and $0,35 \mathrm{~m}$ for the base width $B W .1$ and $B S 2 A$. The measurement for the canal design based on periodic flow for $B W .1$ and $B S 2 A$ in $Q_{5}, Q_{50}$, and $Q_{100}$ are 2,14m, 2,92m, $3,14 \mathrm{~m}, 1,74 \mathrm{~m}, 2,17 \mathrm{~m}$, and 2,34m. The top width $(b)$ measurement of the divider BW.1 and reservoir $B S 2 A$ construction are $0,44 m$ and $0,24 m$. The measurement of its width in $Q_{5}, Q_{50}$, and $Q_{100}$ are $1,78 \mathrm{~m}, 2,44 \mathrm{~m}, 2,60 \mathrm{~m}, 1,50 \mathrm{~m}, 2,20 \mathrm{~m}$, and 2,34 $\mathrm{m}$.
\end{abstract}

Keywords: air kemumu weir, dimension, periodic flow

Email:Inersia@unib.ac.id 


\section{PENDAHULUAN}

Irigasi berperan penting dalam menunjang produksi bahan pangan. Irigasi bertujuan mengalirkan air untuk keperluan pertanian dan membagi air ke sawah-sawah serta membuang air yang tidak diperlukan lagi melalui saluran pembuang. Sistem irigasi yang baik merupakan salah satu upaya untuk meningkatkan hasil pertanian. Sistem jaringan irigasi yang baik sangat diperlukan untuk menunjang ketersediaan air yang lebih optimal, sehingga air dapat didistribusikan dengan baik dan dapat memenuhi semua areal pertanian yang sudah direncanakan.

Bendung Air Kemumu terletak di desa Kemumu, Kecamatan Arma Jaya, Kabupaten Bengkulu Utara. Bendung Kemumu mengaliri lahan pertanian seluas 1286 Hektar, pada bendung ini terdapat bangunan bagi dan bangunan sadap yang berfungsi untuk membagi dan menyadap air ke areal persawahan. Sedimentasi pada saluran irigasi dan retaknya dinding saluran mengakibatkan kapasitas aliran air ke lahan pertanian tidak optimal dan penyumbatan aliran air dapat menyebabkan banjir pada saat hujan deras. Kerusakan pada pintu-pintu bangunan bagi dan sadap pada bendung ini menyebabkan tidak terkontrolnya jumlah air pada saluran.

Penelitian sebelumnya yang dilakukan oleh Sari (2015), tentang analisis saluran sekunder dan bangunan distribusi pada Bendung Air Hitam Kiri, Kabupaten Bengkulu Tengah. Perencanaan saluran dan bangunan distribusi pada penelitian tersebut berdasarkan pengukuran debit yang dilakukan dengan menggunakan perhitungan nilai NFR (kebutuhan air di sawah) yang dihitung terlebih dahulu.

Penelitian yang sudah dilakukan di lokasi Bendung Air Kemumu yaitu penelitian yang dilakukan oleh Bezzel (2017) tentang analisis kehilangan air di saluran primer. Penelitian ini bertujuan untuk menghitung kehilangan air irigasi yang terjadi akibat rembesan, evaporasi dan debit saluran pada saluran primer dan pengaruhnya terhadap kehilangan air irigasi. Penelitian lainnya di lokasi yang sama juga dilakukan oleh Rahayu (2017) tentang efisiensi air irigasi. Penelitian ini bertujuan untuk menghitung nilai efisiensi penyaluran air pada saluran sekunder dan tersier di daerah irigasi Kemumu.

Penelitian yang sudah dilakukan sebelumnya di lokasi Bendung Air Kemumu belum ada yang merencanakan saluran, bangunan bagi dan bangunan sadap berdasarkan debit kala ulang. Debit kala ulang ini digunakan sebagai dasar untuk penentuan kapasitas dan dimensi saluran dan bangunan distribusi sehingga tidak terjadi kerusakan selama besaran dimensi yang direncanakan sesuai dengan debit kala ulang rencananya. Perencanaan ulang berdasarkan debit kala ulang ini bertujuan untuk mengetahui besarnya dimensi saluran, bangunan bagi dan bangunan sadap berdasarkan debit kala ulang 5 tahun, 50 tahun, dan 100 tahun.

\section{Analisis curah hujan}

Data curah hujan sangat penting untuk perencanaan teknik khususnya untuk bangunan air misalnya irigasi, bendungan, drainase perkotaan, pelabuhan, dermaga, dan lain-lain. Oleh karena itu data curah hujan di suatu daerah dicatat terus menerus untuk menghitung perencanaan yang akan dilakukan. Diperlukan data curah hujan bertahun-tahun untuk mendapatkan perhitungan perencanaan yang akurat, semakin banyak data curah hujan yang ada maka semakin akurat perhitungan yang akan dilakukan (Prawaka, 2016).

Data hujan yang diperoleh dari alat penakar hujan merupakan hujan yang terjadi hanya pada suatu tempat atau titik saja. Hujan sangat bervariasi terhadap tempat, maka untuk kawasan yang luas, satu alat penakar hujan belum dapat menggambarkan hujan 
wilayah tersebut. Dalam hal ini diperlukan hujan kawasan yang diperoleh dari harga rata-rata curah hujan beberapa stasiun penakar hujan yang ada di dalam dan/atau di sekitar kawasan tersebut. Ada tiga macam metode yang dipakai dalam menghitung hujan rata-rata kawasan yaitu rata-rata aljabar, poligon Thiessen, dan Isohyet (Suripin, 2004).

\section{Saluran irigasi}

Berdasarkan Standar Perencanaan Irigasi bagian jaringan irigasi KP-01, saluran irigasi dapat didefenisikan sebagai berikut:

1. Saluran primer yaitu saluran yang membawa air dari jaringan utama ke saluran sekunder dan ke petak-petak tersier yang dialiri.

2. Saluran sekunder yaitu saluran yang membawa air dari saluran primer ke petak-petak tersier yang dilayani oleh saluran sekunder tersebut.

3. Saluran tersier yaitu saluran yang membawa air dari bangunan sadap tersier di jaringan utama ke dalam petak tersier lalu kesaluran kuarter.

\section{Bangunan bagi dan bangunan sadap}

Bangunan bagi adalah sebuah bangunan yang berfungsi untuk membagi air dari saluran primer atau saluran sekunder ke dua buah saluran atau lebih yang masing-masing debitnya lebih kecil. Bangunan bagi terletak pada saluran primer atau pada saluran sekunder pada suatu titik cabang (Mawardi, 2010).

Bangunan sadap merupakan bangunan yang digunakan untuk menyadap air dari saluran primer ke saluran sekunder atau saluran sekunder ke saluran tersier. Bangunan sadap yang menyadap aliran dari saluran primer ke saluran sekunder disebut bangunan sadap sekunder yang terletak di saluran primer. Bangunan sadap yang menyadap aliran dari sekunder ke saluran tersier disebut bangunan sadap tersier yang terletak di saluran sekunder (Mawardi, 2010).

\section{METODE PENELITIAN}

\section{Lokasi penelitian}

Penelitian ini dilakukan pada Daerah Irigasi Bendung Air Kemumu yang terletak di Desa Kemumu Kecamatan Arma Jaya Kabupaten Bengkulu Utara.

\section{Data dan sumber data}

Data yang digunakan pada penelitian ini berupa data primer dan sekunder. Data primer berupa data dimensi saluran, bangunan bagi dan sadap, serta kondisi/kerusakan bangunan bagi dan bangunan sadap yang diperoleh dari pengukuran dan pengamatan langsung di lapangan. Data sekunder berupa data curah hujan selama 10 tahun terakhir (2007-2016) beserta 3 pos stasiun hujan terdekat diperoleh dari BWS Sumatera VII Provinsi Bengkulu dan peta skema jaringan irigasi bendung Air Kemumu diperoleh dari Dinas Pekerjaan Umum.

Tahapan pelaksanaan penelitian:

a. Studi pustaka

b. Menetapkan lokasi penelitian yang akan dilakukan (survei pendahuluan)

c. Melakukan pengukuran (survei lapangan)

\section{HASIL DAN PEMBAHASAN}

Perhitungan intensitas curah hujan $\left(I_{t}\right)$ pada saluran sekunder

Panjang saluran sekunder $(\mathrm{L})=0,043 \mathrm{~km}$

Koefisien Strickler $(\mathrm{K}) \quad=35$

Kecepatan aliran (v) $\quad=0,304 \mathrm{~m} / \mathrm{det}$

1. Luas penampang basah saluran:

$$
\begin{aligned}
\mathrm{A} & =\mathrm{h}(\mathrm{b}+\mathrm{m} \cdot \mathrm{h}) \\
& =0,40(1,1+(1,5 \times 0,40)) \\
& =0,68 \mathrm{~m}^{2}
\end{aligned}
$$

2. Keliling penampang basah saluran:

$$
\begin{aligned}
\mathrm{P} & =\mathrm{b}+2 \mathrm{~h}\left(1+\mathrm{m}^{2}\right)^{0,5} \\
& =1,1+2(0,40)\left(\left(1+1,5^{2}\right)^{0,5}\right) \\
& =2,54 \mathrm{~m}
\end{aligned}
$$

3. Jari-jari hidrolis:

$$
\begin{aligned}
\mathrm{R} & =\mathrm{A} / \mathrm{P} \\
& =0,68 / 2,54
\end{aligned}
$$




$$
=0,27 \mathrm{~m}
$$

4. Kemiringan dasar saluran (S) dihitung dengan rumus Strikler:

$$
S=\left(\frac{V}{K \times R^{\frac{2}{3}}}\right)^{2}=\left(\frac{0,304}{35 \times 0,27^{\frac{2}{3}}}\right)^{2}=0,00043
$$

5. Nilai $t_{c}$ dihitung dengan menggunakan persamaan Kirpich:

$$
\begin{aligned}
\text { tc } & =\left(\frac{0,87 \times L^{2}}{1000 \times S}\right)^{0,385} \\
& =\left(\frac{0,87 \times 0,043^{2}}{1000 \times 0,00043}\right)^{0,385} \\
& =0,116 \mathrm{jam}
\end{aligned}
$$

6. Intensitas curah hujan dihitung dengan menggunakan rumus Mononobe:

$$
\begin{aligned}
& I_{5}=\frac{R_{5}}{24}\left[\frac{24}{\mathrm{tc}}\right]^{2 / 3} \\
& I_{5}=\frac{166,236}{24}\left[\frac{24}{0,116}\right]^{2 / 3} \\
& I_{5}=242,29 \mathrm{~mm} / \mathrm{jam}
\end{aligned}
$$

Perhitungan Intensitas Curah Hujan pada saluran sekunder dapat dilihat Tabel 1.

Tabel 1. Perhitungan Intensitas Curah Hujan $\left(\mathrm{I}_{\mathrm{t}}\right)$ pada Saluran Sekunder

\begin{tabular}{|c|c|c|}
\hline Kala Ulang & $\begin{array}{c}\mathrm{R} \\
(\mathrm{mm})\end{array}$ & $\begin{array}{c}\mathrm{I}_{\mathrm{t}} \\
(\mathrm{mm} / \mathrm{jam})\end{array}$ \\
\hline 5 tahun & 166,236 & 242,29 \\
\hline 50 tahun & 261,381 & 380,97 \\
\hline 100 tahun & 289,038 & 421,28 \\
\hline
\end{tabular}

Perhitungan intensitas curah hujan $\left(I_{t}\right)$ pada saluran tersier

Panjang saluran tersier $\quad=0,021 \mathrm{~km}$

Koefisien Strickler $(\mathrm{K}) \quad=35$

Kecepatan aliran (v) $\quad=0,225 \mathrm{~m} / \mathrm{det}$

1. Luas penampang basah saluran:

$$
\begin{aligned}
\mathrm{A} & =\mathrm{h}(\mathrm{b}+\mathrm{m} \cdot \mathrm{h}) \\
& =0,25(0,75+(1 \times 0,25)) \\
& =0,25 \mathrm{~m}^{2}
\end{aligned}
$$

2. Keliling penampang basah saluran:

$$
\begin{aligned}
\mathrm{P} & =\mathrm{b}+2 \mathrm{~h}\left(1+\mathrm{m}^{2}\right)^{0,5} \\
& =0,75+2(0,25)\left(\left(1+1^{2}\right)^{0,5}\right) \\
& =1,45 \mathrm{~m}
\end{aligned}
$$

3. Jari-jari hidrolis:

$$
\begin{aligned}
\mathrm{R} & =\mathrm{A} / \mathrm{P} \\
& =0,25 / 1,45 \\
& =0,17 \mathrm{~m}
\end{aligned}
$$

4. Kemiringan dasar saluran (S) dihitung dengan rumus Strikler:

$$
\mathrm{S}=\left(\frac{V}{K \times R^{\frac{2}{3}}}\right)^{2}=\left(\frac{0,225}{35 \times 0,17^{\frac{2}{3}}}\right)^{2}=0,00044
$$

5. Nilai $t_{c}$ dihitung dengan menggunakan persamaan Kirpich:

$$
\begin{aligned}
\text { tc } & =\left(\frac{0,87 \times L^{2}}{1000 \times S}\right)^{0,385} \\
& =\left(\frac{0,87 \times 0,021}{1000 \times 0,00044}^{2}\right)^{0,385} \\
& =0,066 \mathrm{jam}
\end{aligned}
$$

6. Intensitas curah hujan dihitung dengan menggunakan rumus Mononobe:

$$
\begin{aligned}
& \mathrm{I}_{5}=\frac{\mathrm{R}_{5}}{24}\left[\frac{24}{\mathrm{tc}}\right]^{2 / 3} \\
& \mathrm{I}_{5}=\frac{166,236}{24}\left[\frac{24}{0,066}\right]^{2 / 3} \\
& \mathrm{I}_{5}=352,87 \mathrm{~mm} / \mathrm{jam}
\end{aligned}
$$

Perhitungan Intensitas Curah Hujan pada saluran sekunder dapat dilihat Tabel 2.

Tabel 2. Perhitungan Intensitas Curah Hujan $\left(\mathrm{I}_{\mathrm{t}}\right)$ pada Saluran Tersier

\begin{tabular}{|c|c|c|}
\hline Kala Ulang & $\begin{array}{c}\mathrm{R} \\
(\mathrm{mm})\end{array}$ & $\begin{array}{c}\mathrm{I}_{\mathrm{t}} \\
(\mathrm{mm} / \mathrm{jam})\end{array}$ \\
\hline 5 tahun & 166,236 & 352,87 \\
\hline 50 tahun & 261,381 & 554,84 \\
\hline 100 tahun & 289,038 & 613,55 \\
\hline
\end{tabular}

\section{Analisis kecepatan aliran di lapangan}

Pengukuran yang dilakukan untuk mendapatkan debit saluran pada penelitian ini yaitu pengukuran kecepatan air dengan menggunakan alat currentmeter. Hasil Pengukuran kecepatan air pada saluran sekunder BW.1 dan tersier BS 2A dapat dilihat pada Tabel 3 dan Tabel 4.

Tabel 3. Perhitungan Kecepatan Aliran di Saluran Sekunder BW.1

\begin{tabular}{|c|c|c|c|c|c|}
\hline No & $\begin{array}{c}\text { Jumlah } \\
\text { putaran } \\
\text { rata-rata }\end{array}$ & Waktu & $\mathrm{N}$ & $\begin{array}{c}\mathrm{n} \\
\text { tabel }\end{array}$ & Kecepatan \\
$(\mathrm{v})$
\end{tabular}




\begin{tabular}{|c|c|c|c|c|c|}
\hline 3 & 225 & 50 & 4,5 & 1,157 & 0,300 \\
\hline \multicolumn{4}{|c|}{ Jumlah Kecepatan } & 0,912 \\
\hline $\begin{array}{c}\text { Kecepatan rata-rata ( Jumlah } \\
\text { Kecepatan : 3 ) }\end{array}$ & 0,304 \\
\hline \multicolumn{3}{|c|}{}
\end{tabular}

Tabel 4. Perhitungan Kecepatan Aliran di Saluran Tersier BS 2A.

\begin{tabular}{|c|c|c|c|c|c|}
\hline No & $\begin{array}{c}\text { Jumlah } \\
\text { putaran } \\
\text { rata-rata }\end{array}$ & Waktu & $\mathrm{n}$ & $\begin{array}{c}\mathrm{n} \\
\text { tabel }\end{array}$ & Kecepatan \\
$(\mathrm{v})$
\end{tabular}

Desain saluran sekunder dan tersier perhitungan berdasarkan debit saluran di lapangan

Perhitungan saluran sekunder (BW.1)

1. Tinggi muka air $(\mathrm{h}) \quad=0,40 \mathrm{~m}$

2. Lebar saluran (b) $\quad=1,1 \mathrm{~m}$

3. Kecepatan aliran (v) $=0,304 \mathrm{~m} / \mathrm{det}$

4. Kemiringan saluran $(m)=1,5$

Setelah memperoleh data dengan pengukuran dilapangan, maka dapat menghitung Luas (A), dan Debit (Q) sebagai berikut:

1) Luas penampang basah saluran:

$$
\begin{aligned}
\mathrm{A} & =\mathrm{h}(\mathrm{b}+\mathrm{m} \cdot \mathrm{h}) \\
& =0,40(1,1+(1,5 \times 0,40)) \\
& =0,68 \mathrm{~m}^{2}
\end{aligned}
$$

2) Debit saluran:

$$
\begin{aligned}
\mathrm{Q} & =\mathrm{A} \times \mathrm{v} \\
& =0,68 \times 0,304 \\
& =0,21 \mathrm{~m}^{3} / \mathrm{det}
\end{aligned}
$$

3) Menentukan nilai $n, v$ dan m dengan cara interpolasi dengan nilai
$\mathrm{Q}=0,21 \mathrm{~m}^{3} /$ detik dan nilai Koefisien Strickler $(\mathrm{K})=35$

Tabel 5. Interpolasi Nilai $n$ Berdasarkan Nilai Q pada BW.1 Debit Saluran.

\begin{tabular}{|l|c|}
\hline $\mathrm{Q}\left(\mathrm{m}^{3} / \mathrm{dtk}\right)$ & $\mathrm{n}=\mathrm{b} / \mathrm{h}$ \\
\hline 0,15 & 1 \\
\hline 0,21 & $\mathrm{n}$ \\
\hline 0,30 & 1 \\
\hline $\mathrm{n} \quad=1+\frac{(1-1)}{(0,30-0,15)} x(0,21-0,15)$ \\
$\quad=1 \mathrm{~m} / \mathrm{dtk}$ \\
$\mathrm{n} \quad=\mathrm{b} / \mathrm{h}=1$ \\
$\mathrm{~b}=1 \mathrm{~h}$
\end{tabular}

Tabel 6. Interpolasi Nilai $\mathrm{v}$ Berdasarkan Nilai Q pada BW.1 Debit Saluran

\begin{tabular}{|c|c|}
\hline $\mathrm{Q}\left(\mathrm{m}^{3} / \mathrm{dtk}\right)$ & $\mathrm{v}(\mathrm{m} / \mathrm{dtk})$ \\
\hline 0,15 & 0,30 \\
\hline 0,21 & $\mathrm{~V}$ \\
\hline 0,30 & 0,35 \\
\hline
\end{tabular}

Hasil Interpolasi:

$$
\begin{aligned}
\mathrm{V} & =0,30+\frac{(0,35-0,30)}{(0,30-0,15)} \times(0,21-0,15) \\
& =0,320 \mathrm{~m} / \mathrm{dtk}
\end{aligned}
$$

4) Menghitung luas penampang basah:
$\mathrm{A}=(\mathrm{b}+\mathrm{m} . \mathrm{h}) \times \mathrm{h}$
$A=(1 \mathrm{~h}+1.5 \mathrm{~h}) \times \mathrm{h}$
$A=2,5 h^{2}$

5) Harga $h$ dapat diketahui dengan menggunakan rumus mencari debit (Q):

$$
\begin{aligned}
\mathrm{Q} & =\mathrm{A} \times \mathrm{V} \\
0,22 & =2,5 \mathrm{~h}^{2} \times 0,320 \\
0,68 & =2,5 \mathrm{~h}^{2} \\
\mathrm{~h} & =\sqrt{\frac{0,68}{2,5}} \\
\mathrm{~h} & =0,52 \mathrm{~m}
\end{aligned}
$$

6) Menghitung nilai lebar dasar saluran (b) kemudian dari nilai b yang 
dihasilkan, dapat dihitung nilai luas penampang basah $(\mathrm{A})$ :
$\mathrm{b} \quad=1 \mathrm{~h}$
$\mathrm{b}=1 \times 0,52$
$\mathrm{b}=0,52 \mathrm{~m}$
A $=2,5 \mathrm{~h}^{2}$
$\mathrm{A}=2,5(0,52)^{2}$
A $=0,68 \mathrm{~m}^{2}$

7) Menghitung keliling penampang basah saluran:

$$
\begin{aligned}
& \mathrm{P}=\mathrm{b}+2 \mathrm{~h}\left(1+\mathrm{m}^{2}\right)^{0,5} \\
& \mathrm{P}=0,52+2(0,52)\left(\left(1+1,5^{2}\right)^{0,5}\right) \\
& \mathrm{P}=2,39 \mathrm{~m}
\end{aligned}
$$

8) Menghitung jari-jari hidrolis dari nilai luas penampang basah (A) dan nilai keliling penampang basah saluran $(\mathrm{P})$ :

$$
\begin{aligned}
& \mathrm{R}=\mathrm{A} / \mathrm{P} \\
& \mathrm{R}=0,68 / 2,39 \\
& \mathrm{R}=0,28 \mathrm{~m}
\end{aligned}
$$

9) Menentukan nilai kemiringan dasar saluran menggunakan rumus Strikler namun dengan nilai $K, \mathrm{R}$ dan $\mathrm{v}$ yang telah diketahui:

$$
\begin{aligned}
\mathrm{I} & =\left(\frac{V}{K \times R^{\frac{2}{3}}}\right)^{2} \\
& =\left(\frac{0,320}{35 \times 0,28^{2 / 3}}\right)^{2}=0,00045 \\
\mathrm{~V} & =K \times R^{2 / 3} \times I^{1 / 2} \\
& =35 \times 0,28^{\frac{2}{3}} \times 0,00045^{\frac{1}{2}}
\end{aligned}
$$

$$
=0,320 \mathrm{~m} / \mathrm{dt}
$$

10) Membandingkan nilai kecepatan aliran dengan rumus Manning dan rumus Chezy:

\section{Rumus Manning:}

$$
\begin{aligned}
\mathrm{I} & =\left(\frac{0,320}{\frac{1}{0,025} \times 0,28^{\frac{2}{3}}}\right)^{2}=0,00035 \\
\mathrm{~V} & =\frac{1}{\mathrm{n}} \times \mathrm{R}^{2 / 3} \times \mathrm{S}^{1 / 2} \\
& =\frac{1}{0,025} \times 0,28^{2 / 3} \times 0,00035^{1 / 2} \\
& =\mathbf{0 , 3 2 0} \mathbf{~} / \mathbf{d t}
\end{aligned}
$$

\section{Rumus Chezy:}

$$
\begin{aligned}
& \mathrm{C}=\frac{1}{n} R^{\frac{1}{6}}=\frac{1}{0,025} 0,28^{\frac{1}{6}}=32,35 \\
& \mathrm{~V}=\mathrm{C} \sqrt{R \times I}=32,35 \\
& \sqrt{0,28 \times 0,00035}=\mathbf{0 , 3 2 0} \mathbf{~ m} / \mathbf{d t}
\end{aligned}
$$

Hasil perhitungan kecepatan aliran dengan rumus strikler didapat nilai $\mathrm{v}$ sebesar 0,320 sedangkan dengan rumus manning dan chezy didapat nilai $\mathrm{v}$ sebesar 0,320. Dilihat dari perhitungan di atas bahwa nilai $\mathrm{v}$ dari ketiga rumus sama, maka perhitungan diatas sudah benar.

Rekapitulasi hasil perhitungan desain saluran sekunder dan sersier berdasarkan debit saluran di lapangan dapat dilihat pada Tabel 7.

Tabel 7. Rekapitulasi Hasil Perhitungan Desain Saluran Sekunder dan Tersier Berdasarkan Debit Saluran di Lapangan

\begin{tabular}{|c|c|c|c|c|c|c|c|c|}
\hline Saluran & $\begin{array}{c}\mathrm{Q} \\
\left(\mathrm{m}^{3} / \mathrm{dtk}\right)\end{array}$ & $\begin{array}{c}\mathrm{V} \\
(\mathrm{m} / \mathrm{dtk})\end{array}$ & $\begin{array}{c}\mathrm{b} \\
(\mathrm{m})\end{array}$ & $\begin{array}{c}\mathrm{H} \\
(\mathrm{m})\end{array}$ & $\begin{array}{c}\mathrm{A} \\
\left(\mathrm{m}^{2}\right)\end{array}$ & $\begin{array}{c}\mathrm{P} \\
(\mathrm{m})\end{array}$ & $\begin{array}{c}\mathrm{R} \\
(\mathrm{m})\end{array}$ & $\mathrm{I}$ \\
\hline BW.1 & 0,21 & 0,320 & 0,52 & 0,52 & 0,68 & 2,39 & 0,28 & 0,00045 \\
\hline BS 2A & 0,06 & 0,255 & 0,35 & 0,35 & 0,25 & 1,34 & 0,19 & 0,00048 \\
\hline
\end{tabular}

Perhitungan berdasarkan debit kala ulang rencana

\section{a. Perhitungan saluran sekunder (BW.1)}

1. Koefisien pengaliran $(\mathrm{C}) \quad=0,15$

2. Intensitas hujan $\left(\mathrm{I}_{5}\right) \quad=242,29$

3. Luas daerah pengaliran $(\mathrm{A})=0,22$ $\mathrm{Km}^{2}$

Berdasarkan data di atas, maka dapat dihitung debit kala ulang dengan menggunakan metode rasional sebagai berikut:

$$
\begin{aligned}
\mathrm{Q}_{5} & =0,278 \cdot \mathrm{C} . \mathrm{I}_{5} \cdot \mathrm{A} \\
& =0,278 \times 0,15 \times 242,29 \times 0,22 \\
& =2,22 \mathrm{~m}^{3} / \mathrm{det}
\end{aligned}
$$

Perhitungan debit kala ulang $\left(\mathrm{Q}_{\mathrm{T}}\right)$ berdasarkan periode ulang rencana menggunakan metode rasional selengkapnya disajikan pada Tabel 8 sebagai berikut: 
Tabel 8. Debit periode kala ulang dengan metode rasional (BW.1)

\begin{tabular}{|c|c|c|c|c|c|}
\hline $\begin{array}{c}\text { Kala } \\
\text { Ulang }\end{array}$ & $\begin{array}{c}\text { Koef. } \\
\text { Penyesuaian } \\
\text { Metrik }\end{array}$ & $\begin{array}{c}\mathrm{C} \\
\text { rata-rata } \\
(\mathrm{mm})\end{array}$ & $\begin{array}{c}\mathrm{I}_{\mathrm{t}} \\
(\mathrm{mm} / \\
\mathrm{jam})\end{array}$ & $\mathrm{A}$ & $\mathrm{Q}_{\mathrm{T}}$ \\
\hline 5 & 0,278 & 0,15 & 242,29 & 0,22 & 2,22 \\
\hline 50 & 0,278 & 0,15 & 380,97 & 0,22 & 3,49 \\
\hline 100 & 0,278 & 0,15 & 421,28 & 0,22 & 3,86 \\
\hline
\end{tabular}

Berdasarkan debit kala ulang rencana 5, 50, dan 100 tahun maka dapat dihitung dimensi saluran sekunder BW.1 sebagai berikut:

1. Menentukan nilai $\mathrm{n}, \mathrm{v}$ dan $\mathrm{m}$ dengan cara interpolasi menggunakan Tabel 2.5 dan 2.6 hubungan antara $\mathrm{Q}$, dengan $\mathrm{n}, \mathrm{v}$ dan $\mathrm{m}$. Untuk $\mathrm{Q}_{5}=2,22$ $\mathrm{m}^{3} /$ detik, berdasarkan tabel dengan cara interpolasi diperoleh:

Koefisien Strickler $(\mathrm{K})=40$

$1: \mathrm{m}$

$=1: 1,5$

Tabel 9. Interpolasi Nilai $n$ Berdasarkan Nilai Q pada BW.1 Debit Kala Ulang

\begin{tabular}{|c|c|}
\hline $\mathrm{Q}\left(\mathrm{m}^{3} / \mathrm{dtk}\right)$ & $\mathrm{n}=\mathrm{b} / \mathrm{h}$ \\
\hline 1,50 & 1,8 \\
\hline 2,22 & $\mathrm{~N}$ \\
\hline 3,00 & 2,3 \\
\hline
\end{tabular}

$\mathrm{n}=1,8+\frac{(2,3-1,8)}{(3,00-1,50)} x(2,22-1,50)$

$=2,04 \mathrm{~m} / \mathrm{dtk}$

$\mathrm{n}=\mathrm{b} / \mathrm{h}=2,04$

$\mathrm{b}=2,04 \mathrm{~h}$

Tabel 10. Interpolasi Nilai $v$ Berdasarkan Nilai Q pada BW.1 Debit Kala Ulang

\begin{tabular}{|c|c|}
\hline $\mathrm{Q}\left(\mathrm{m}^{3} / \mathrm{dtk}\right)$ & $\mathrm{v}(\mathrm{m} / \mathrm{dtk})$ \\
\hline 1,50 & 0,55 \\
\hline 2,22 & $\mathrm{~V}$ \\
\hline 3,00 & 0,60 \\
\hline
\end{tabular}

Hasil Interpolasi:

$$
\begin{aligned}
\mathrm{v} & =0,55+\frac{(0,60-0,55)}{(3,00-1,50)} \times(2,22-1,50) \\
& =0,57 \mathrm{~m} / \mathrm{dtk}
\end{aligned}
$$

2. Menghitung luas penampang basah:
$\mathrm{A}=(\mathrm{b}+\mathrm{m} . \mathrm{h}) \times \mathrm{h}$
$A=(2,04 h+1,5 . h) \times h$
$\mathrm{A}=3,54 \mathrm{~h}^{2}$

3. Harga $h$ dapat diketahui dengan menggunakan rumus mencari debit (Q):

$\mathrm{Q}=\mathrm{A} \times \mathrm{V}$

$2,22=3,54 \mathrm{~h}^{2} \times 0,57$

$3,89=3,54 \mathrm{~h}^{2}$

$\mathrm{h}=\sqrt{\frac{3,89}{3,54}}$

$\mathrm{h} \quad=1,05 \mathrm{~m}$

4. Menghitung nilai lebar dasar saluran (b) kemudian dari nilai b yang dihasilkan, dapat dihitung nilai luas penampang basah $(\mathrm{A})$ :
$\mathrm{b}=2,04 \mathrm{~h}$
$\mathrm{b}=2,04 \times 1,05$
$\mathrm{b}=2,14 \mathrm{~m}$
$\mathrm{A}=3,54 \mathrm{~h}^{2}$
$\mathrm{A}=3,54(1,05)^{2}$
$A=3,90 \mathrm{~m}^{2}$

5. Menghitung keliling penampang basah saluran:

$$
\begin{aligned}
& \mathrm{P}=\mathrm{b}+2 \mathrm{~h}\left(1+\mathrm{m}^{2}\right)^{0,5} \\
& \mathrm{P}=2,14+2 \cdot(1,05)\left(\left(1+1,5^{2}\right)^{0,5}\right) \\
& \mathrm{P}=5,92 \mathrm{~m}
\end{aligned}
$$

6. Menghitung jari-jari hidrolis dari nilai luas penampang basah (A) dan nilai keliling penampang basah saluran $(\mathrm{P})$ :
$\mathrm{R}=\mathrm{A} / \mathrm{P}$
$\mathrm{R}=3,90 / 5,92$
$\mathrm{R}=0,66 \mathrm{~m}$

7. Menentukan nilai kemiringan dasar saluran menggunakan rumus Strikler namun dengan nilai $\mathrm{K}, \mathrm{R}$ dan $\mathrm{v}$ yang telah diketahui:

$$
\begin{aligned}
I & =\left(\frac{V}{K \times R^{\frac{2}{3}}}\right)^{2}=\left(\frac{0,57}{40 \times 0,66^{\frac{2}{3}}}\right)^{2} \\
& =0,00035
\end{aligned}
$$




$$
\begin{aligned}
\mathrm{V} & =K \times R^{2 / 3} \times I^{1 / 2} \\
& =40 \times 0,66^{2 / 3} \times 0,00035^{1 / 2} \\
& =\mathbf{0 , 5 7} \mathbf{~} / \mathbf{d t}
\end{aligned}
$$

8. Membandingkan nilai kecepatan aliran dengan rumus Manning dan rumus Chezy:

\section{Rumus Manning:}

$$
\begin{aligned}
\mathrm{I} & =\left(\frac{0,57}{\frac{1}{0,025} \times 0,66^{\frac{2}{3}}}\right)^{2}=0,00035 \\
\mathrm{~V} & =\frac{1}{\mathrm{n}} \times \mathrm{R}^{2 / 3} \times \mathrm{S} \mathrm{S}^{1 / 2} \\
& =\frac{1}{0,025} \times 0,66^{2 / 3} \times 0,00035^{1 / 2} \\
& =\mathbf{0 , 5 7} \mathbf{~ m} / \mathbf{d t}
\end{aligned}
$$

Rumus Chezy:

$$
\begin{aligned}
& \mathrm{C}=\frac{1}{n} R^{\frac{1}{6}}=\frac{1}{0,025} 0,66^{\frac{1}{6}}=37,32 \\
& \mathrm{~V}=\mathrm{C} \sqrt{R \times I}=37,32 \\
& \sqrt{0,66 \times 0,00035}=\mathbf{0 , 5 7} \mathbf{~ m} / \mathbf{d t}
\end{aligned}
$$

Hasil perhitungan kecepatan aliran dengan rumus strikler didapat nilai $\mathrm{v}$ sebesar 0,57 sedangkan dengan rumus manning dan chezy didapat nilai $\mathrm{v}$ sebesar 0,57. Dilihat dari perhitungan di atas bahwa nilai $\mathrm{v}$ dari ketiga rumus sama, maka perhitungan diatas sudah benar.

Rekapitulasi hasil perhitungan desain saluran sekunder selengkapnya disajikan pada Tabel 11.

Tabel 11. Rekapitulasi Hasil Perhitungan Desain Saluran Sekunder Berdasarkan Debit Kala Ulang Rencana

\begin{tabular}{|c|c|c|c|c|c|c|c|c|}
\hline Saluran & $\begin{array}{c}\mathrm{Q} \\
\left(\mathrm{m}^{3} / \mathrm{dtk}\right)\end{array}$ & $\begin{array}{c}\mathrm{V} \\
(\mathrm{m} / \mathrm{dtk})\end{array}$ & $\begin{array}{c}\mathrm{b} \\
(\mathrm{m})\end{array}$ & $\begin{array}{c}\mathrm{h} \\
(\mathrm{m})\end{array}$ & $\begin{array}{c}\mathrm{A} \\
\left(\mathrm{m}^{2}\right)\end{array}$ & $\begin{array}{c}\mathrm{P} \\
(\mathrm{m})\end{array}$ & $\begin{array}{c}\mathrm{R} \\
(\mathrm{m})\end{array}$ & $\mathrm{I}$ \\
\hline \multirow{3}{*}{ BW.1 } & 2,22 & 0,57 & 2,14 & 1,05 & 3,90 & 5,92 & 0,66 & 0,00035 \\
\cline { 2 - 9 } & 3,49 & 0,61 & 2,92 & 1,20 & 5,65 & 7,25 & 0,77 & 0,00033 \\
\cline { 2 - 9 } & 3,86 & 0,62 & 3,14 & 1,24 & 6,19 & 7,61 & 0,81 & 0,00031 \\
\hline
\end{tabular}

\section{b. Perhitungan Saluran Tersier (BS 2A)}

1. Koefisien pengaliran $(\mathrm{C}) \quad=0,15$

2. Intensitas hujan $\left(\mathrm{I}_{5}\right) \quad=352,87$

3. Luas daerah pengaliran $(\mathrm{A})=0,10 \mathrm{~km}^{2}$

Berdasarkan data di atas, maka dapat dihitung debit kala ulang dengan menggunakan metode rasional sebagai berikut:

$$
\begin{aligned}
\mathrm{Q}_{5} & =0,278 \cdot \mathrm{C} \cdot \mathrm{I}_{5} \cdot \mathrm{A} \\
& =0,278 \times 0,15 \times 352,87 \times 0,10 \\
& =1,47 \mathrm{~m}^{3} / \mathrm{det}
\end{aligned}
$$

Perhitungan debit kala ulang $\left(\mathrm{Q}_{\mathrm{T}}\right)$ berdasarkan periode ulang rencana menggunkan metode rasional selengkapnya disajikan pada Tabel 12.
Tabel 12. Debit periode kala ulang dengan metode rasional (BS 2A)

\begin{tabular}{|c|c|c|c|c|c|}
\hline $\begin{array}{c}\text { Kala } \\
\text { Ulang }\end{array}$ & $\begin{array}{c}\text { Koef. } \\
\text { Penyesuaian } \\
\text { Metrik }\end{array}$ & $\begin{array}{c}\mathrm{C} \\
(\mathrm{mm})\end{array}$ & $\begin{array}{c}\mathrm{I}_{\mathrm{t}} \\
(\mathrm{mm} / \\
\mathrm{jam})\end{array}$ & $\begin{array}{c}\mathrm{A} \\
(\mathrm{km})\end{array}$ & $\begin{array}{c}\mathrm{Q}_{\mathrm{T}} \\
\left(\mathrm{m}^{3} / \mathrm{dtk}\right)\end{array}$ \\
\hline 5 & 0,278 & 0,15 & 352,87 & 0,10 & 1,47 \\
\hline 50 & 0,278 & 0,15 & 554,84 & 0,10 & 2,31 \\
\hline 100 & 0,278 & 0,15 & 613,55 & 0,10 & 2,55 \\
\hline
\end{tabular}

Berdasarkan debit kala ulang rencana 5, 50, dan 100 tahun maka dapat dihitung dimensi saluran tersier BS 2A sebagai berikut:

1. Menentukan nilai $\mathrm{n}, \mathrm{v}$ dan $\mathrm{m}$ dengan cara interpolasi menggunakan Tabel 2.5 dan 2.6 hubungan antara Q, dengan $\mathrm{n}$, v dan $\mathrm{m}$. Untuk $\mathrm{Q}_{5}=1,47$ $\mathrm{m}^{3} /$ detik, berdasarkan tabel dengan cara interpolasi diperoleh:
Koefisien Strickler (K)
$=40$
$1: \mathrm{m}$
$=1: 1$ 
Tabel 13. Interpolasi Nilai $n$ Berdasarkan Nilai Q pada BS 2A Debit Kala Ulang

\begin{tabular}{|c|c|}
\hline $\mathrm{Q}\left(\mathrm{m}^{3} / \mathrm{dtk}\right)$ & $\mathrm{n}=\mathrm{b} / \mathrm{h}$ \\
\hline 1,00 & 1,5 \\
\hline 1,47 & $\mathrm{~N}$ \\
\hline & 1,50 \\
\hline $\mathrm{n}$ & $=1,5+\frac{(1,8-1,5)}{(1,50-1,00)} \times(1,47-1,00)$ \\
& $=1,78 \mathrm{~m} / \mathrm{dtk}$ \\
$\mathrm{n}$ & $=\mathrm{b} / \mathrm{h}=1,78$ \\
$\mathrm{~b}$ & $=1,78 \mathrm{~h}$
\end{tabular}

Tabel 14. Interpolasi Nilai $\mathrm{v}$ Berdasarkan Nilai Q pada BS 2A Debit Kala Ulang

\begin{tabular}{|c|c|}
\hline $\mathrm{Q}\left(\mathrm{m}^{3} / \mathrm{dtk}\right)$ & $\mathrm{v}(\mathrm{m} / \mathrm{dtk})$ \\
\hline 0,75 & 0,50 \\
\hline 1,47 & $\mathrm{~V}$ \\
\hline 1,50 & 0,55 \\
\hline
\end{tabular}

Hasil Interpolasi:

$$
\begin{aligned}
\mathrm{v} & =0,50+\frac{(0,55-0,50)}{(1,50-0,75)} \times(1,47-0,75) \\
& =0,54 \mathrm{~m} / \mathrm{dtk}
\end{aligned}
$$

2. Menghitung luas penampang basah :

$$
\begin{aligned}
& A=(b+m . h) \times h \\
& A=(1,78 h+1 . h) \times h \\
& A=2,78 h^{2}
\end{aligned}
$$

3. Harga $h$ dapat diketahui dengan menggunakan rumus mencari debit (Q):

$$
\begin{aligned}
\mathrm{Q} & =\mathrm{A} \times \mathrm{V} \\
1,47 & =2,78 \mathrm{~h}^{2} \times 0,54 \\
2,72 & =2,78 \mathrm{~h}^{2} \\
\mathrm{~h} & =\sqrt{\frac{2,72}{2,78}} \\
\mathrm{~h} & =0,98 \mathrm{~m}
\end{aligned}
$$

4. Menghitung nilai lebar dasar saluran (b) kemudian dari nilai $b$ yang dihasilkan, dapat dihitung nilai luas penampang basah $(\mathrm{A})$ : $\mathrm{b}=1,78 \mathrm{~h}$ b $=1,78 \times 0,98$

$\mathrm{b}=1,74 \mathrm{~m}$

$\mathrm{A}=2,78 \mathrm{~h}^{2}$

$\mathrm{A}=2,78(0,98)^{2}$

$A=2,67 \mathrm{~m}^{2}$

5. Menghitung keliling penampang basah saluran

$$
\begin{aligned}
& \mathrm{P}=\mathrm{b}+2 \mathrm{~h}\left(1+\mathrm{m}^{2}\right)^{0,5} \\
& \mathrm{P}=1,74+2 \cdot(0,98)\left(\left(1+1^{2}\right)^{0,5}\right) \\
& \mathrm{P}=4,51 \mathrm{~m}
\end{aligned}
$$

6. Menghitung jari-jari hidrolis dari nilai luas penampang basah (A) dan nilai keliling penampang basah saluran $(\mathrm{P})$ :

$$
\begin{aligned}
& \mathrm{R}=\mathrm{A} / \mathrm{P} \\
& \mathrm{R}=2,67 / 4,51 \\
& \mathrm{R}=0,59 \mathrm{~m}
\end{aligned}
$$

7. Menentukan nilai kemiringan dasar saluran menggunakan rumus Strikler namun dengan nilai $\mathrm{K}, \mathrm{R}$ dan $\mathrm{v}$ yang telah diketahui:

$$
\begin{aligned}
\mathrm{V} & =K \times R^{2 / 3} \times I^{1 / 2} \\
& =40 \times 0,59^{2 / 3} \times 0,00037^{1 / 2} \\
& =\mathbf{0 , 5 4} \mathbf{~ m / d t} \\
\mathrm{I} & =\left(\frac{V}{K \times R^{\frac{2}{3}}}\right)^{2} \\
& =\left(\frac{0,54}{40 \times 0,59^{2 / 3}}\right)^{2}=0,00037
\end{aligned}
$$

8. Membandingkan nilai kecepatan aliran dengan rumus Manning dan rumus Chezy:

Rumus Manning:

$$
\begin{aligned}
\mathrm{I} & =\left(\frac{0,54}{\frac{1}{0,025} \times 0,59^{\frac{2}{3}}}\right)^{2}=0,00037 \\
\mathrm{~V} & =\frac{1}{\mathrm{n}} \times \mathrm{R}^{2 / 3} \times \mathrm{S}^{1 / 2} \\
& =\frac{1}{0,025} \times 0,59^{2 / 3} \times 0,00037^{1 / 2} \\
& =\mathbf{0 , 5 4} \mathbf{~ m} / \mathbf{d t}
\end{aligned}
$$

\section{Rumus Chezy:}

$\mathrm{C}=\frac{1}{n} R^{\frac{1}{6}}=\frac{1}{0,025} 0,59^{\frac{1}{6}}=36,63$

$\mathrm{V}=\mathrm{C} \sqrt{R \times I}$

$=36,63 \sqrt{0,59 \times 0,00037}$

$=0,54 \mathrm{~m} / \mathrm{dt}$ 
Hasil perhitungan kecepatan aliran dengan rumus strikler didapat nilai $\mathrm{v}$ sebesar 0,54 sedangkan dengan rumus manning dan chezy didapat nilai $\mathrm{v}$ sebesar 0,54. Dilihat dari perhitungan di atas bahwa nilai $\mathrm{v}$ dari ketiga rumus sama, maka perhitungan diatas sudah benar.

Rekapitulasi hasil perhitungan desain saluran tersier selengkapnya disajikan pada Tabel 15.

Tabel 15. Rekapitulasi Hasil Perhitungan Desain Saluran Tersier Berdasarkan Debit Kala Ulang Rencana.

\begin{tabular}{|c|c|c|c|c|c|c|c|c|}
\hline Saluran & $\begin{array}{c}\mathrm{Q} \\
\left(\mathrm{m}^{3} / \mathrm{dtk}\right)\end{array}$ & $\begin{array}{c}\mathrm{V} \\
(\mathrm{m} / \mathrm{dtk})\end{array}$ & $\begin{array}{c}\mathrm{b} \\
(\mathrm{m})\end{array}$ & $\begin{array}{c}\mathrm{H} \\
(\mathrm{m})\end{array}$ & $\begin{array}{c}\mathrm{A} \\
\left(\mathrm{m}^{2}\right)\end{array}$ & $\begin{array}{c}\mathrm{P} \\
(\mathrm{m})\end{array}$ & $\begin{array}{c}\mathrm{R} \\
(\mathrm{m})\end{array}$ & $\mathrm{I}$ \\
\hline \multirow{3}{*}{$\mathrm{BS} 2 \mathrm{~A}$} & 1,47 & 0,54 & 1,74 & 0,98 & 2,67 & 4,51 & 0,59 & 0,00037 \\
\cline { 2 - 9 } & 2,31 & 0,57 & 2,17 & 1,05 & 3,93 & 5,95 & 0,66 & 0,00036 \\
\cline { 2 - 9 } & 2,55 & 0,58 & 2,34 & 1,09 & 4,33 & 6,27 & 0,69 & 0,00035 \\
\hline
\end{tabular}

Perhitungan bangunan bagi dan bangunan sadap

\section{Perhitungan berdasarkan debit} saluran di lapangan

a. Perhitungan hidrolis bangunan bagi (BW.1)

1. Perbedaan tinggi $(\mathrm{z})=0,1 \mathrm{~m}$

2. Koefisien kontraksi dinding, ( $\mu$ ) $=0,85$

3. Debit saluran $(\mathrm{Q})=0,21 \mathrm{~m}^{3} / \mathrm{det}$

Berdasarkan debit saluran di lapangan yang telah dihitung sebelumnya maka dapat dihitung lebar ambang untuk bangunan bagi BW.1 sebagai berikut:

$$
\begin{aligned}
& \mathrm{Q}=\mu \cdot b \cdot h \times \sqrt{2 \cdot g \cdot z} \\
& 0,21=0.85 \times \mathrm{b} \times 0,40 \\
& \mathrm{x} \sqrt{2 \times 9.81 \times 0.1} \\
& \mathrm{~b}=0,44 \mathrm{~m}
\end{aligned}
$$

Jadi, dari data debit saluran yang diperoleh dari hasil perhitungan antara luas penampang (A) dengan kecepatan saluran (v) dapat menghasilkan lebar ambang dengan $b=0,44 \mathrm{~m}$.

\section{b. Perhitungan hidrolis bangunan sadap (BS 2A)}

1. Perbedaan tinggi $(\mathrm{z})=0,07 \mathrm{~m}$

2. Koefisien kontraksi dinding, $(\mu)=0,85$

3. Debit saluran $(\mathrm{Q})=0,06 \mathrm{~m}^{3} / \mathrm{det}$
Berdasarkan debit saluran di lapangan yang telah dihitung, maka dapat dihitung lebar ambang untuk bangunan bagi BS 2A sebagai berikut:

$$
\begin{aligned}
\mathrm{Q} & =\mu \cdot h \times \sqrt{2 \cdot g \cdot z} \\
0,06 & =0.85 \times \mathrm{b} \times 0,25 \sqrt{2 \times 9.81 \times 0.07} \\
\mathrm{~b} \quad & =0,24 \mathrm{~m}
\end{aligned}
$$

Jadi, dari data debit saluran yang diperoleh dari hasil perhitungan antara luas penampang (A) dengan kecepatan saluran (v) dapat menghasilkan lebar ambang dengan $b=0,24 \mathrm{~m}$.

\section{Perhitungan berdasarkan debit kala} ulang rencana

\section{a. Perhitungan desain bangunan bagi} (BW.1)

Berdasarkan debit kala ulang rencana 5, 50, dan 100 tahun yang telah dihitung pada Tabel 4.29 maka dapat dihitung lebar ambang untuk bangunan bagi BW.1 dengan $\mathrm{z}=0,1 \mathrm{~m}$ dan $(\mu)=0,85$ sebagai berikut :

1) Menentukan lebar ambang dengan $\mathrm{Q}_{5}=2,22 \mathrm{~m}^{3} / \mathrm{dtk}$ dan $\mathrm{h}=1,05 \mathrm{~m}$ $\mathrm{Q}=\mu \cdot b . h \times \sqrt{2 \cdot g \cdot z}$ $2,22=0.85 \times$ b x $1,05 \times \sqrt{2 \times 9.81 \times 0.1}$ $\mathrm{b}=1,78 \mathrm{~m}$

2) Menentukan lebar ambang dengan $\mathrm{Q}_{50}=3,49 \mathrm{~m}^{3} / \mathrm{dtk}$ dan $\mathrm{h}=1,20 \mathrm{~m}$ $\mathrm{Q}=\mu \cdot b \cdot h \times \sqrt{2 \cdot g \cdot z}$ $3,49=0.85 \times$ b x $1,20 \times \sqrt{2 \times 9.81 \times 0.1}$ 


$$
\mathrm{b}=2,44 \mathrm{~m}
$$

3) Menentukan lebar ambang dengan $\mathrm{Q}_{100}=3,86 \mathrm{~m}^{3} / \mathrm{dtk}$ dan $\mathrm{h}=1,24 \mathrm{~m}$ $\mathrm{Q} \quad=\mu . b . h \times \sqrt{2 \cdot g \cdot z}$

$3,86=0.85 \times$ b x $1,24 \times \sqrt{2 \times 9.81 \times 0.1}$

$\mathrm{b}=2,60 \mathrm{~m}$

Jadi, dari data debit kala ulang rencana yang diperoleh dari metode rasional dapat menghasilkan lebar ambang untuk $\mathrm{Q}_{5}=$ $2,22 \mathrm{~m}^{3} / \mathrm{dtk}$ dengan $\mathrm{b}=1,78 \mathrm{~m}$, untuk $\mathrm{Q}_{50}=$ $3,49 \mathrm{~m}^{3} / \mathrm{dtk}$ dengan $\mathrm{b}=2,44 \mathrm{~m}$, dan untuk $\mathrm{Q}_{100}=3,86 \quad \mathrm{~m}^{3} / \mathrm{dtk}$ dengan $\mathrm{b}=2,60 \mathrm{~m}$.

\section{b. Perhitungan desain bangunan sadap (BS 2A)}

Berdasarkan debit kala ulang rencana 5, 50, dan 100 tahun yang telah dihitung sebelumnya pada Tabel 4.35 maka dapat dihitung lebar ambang untuk bangunan sadap BS $2 \mathrm{~A}$ dengan $\mathrm{z}=0,07 \mathrm{~m}$ dan $(\mu)=$ 0,85 sebagai berikut :

1) Menentukan lebar ambang dengan $\mathrm{Q}_{5}=1,47 \mathrm{~m}^{3} / \mathrm{dtk}$ dan $\mathrm{h}=0,98 \mathrm{~m}$ $\mathrm{Q}=\mu . b . h \times \sqrt{2 . g \cdot z}$ $1,47=0.85 \times$ b x $0,98 \times \sqrt{2 \times 9.81 \times 0.07}$ $\mathrm{b}=1,50 \mathrm{~m}$

2) Menentukan lebar ambang dengan $\mathrm{Q}_{50}=2,31 \mathrm{~m}^{3} / \mathrm{dtk}$ dan $\mathrm{h}=1,05 \mathrm{~m}$ $\mathrm{Q}=\mu . h \times \sqrt{2 \cdot g \cdot z}$ $2,31=0.85 \times$ b x $1,05 \times \sqrt{2 \times 9.81 \times 0.07}$ $\mathrm{b}=2,20 \mathrm{~m}$

3) Menentukan lebar ambang dengan $\mathrm{Q}_{100}=2,55 \mathrm{~m}^{3} / \mathrm{dtk}$ dan $\mathrm{h}=1,09 \mathrm{~m}$ $\mathrm{Q}=\mu . h \times \sqrt{2 . g \cdot z}$ $2,55=0.85 \times$ b x $1,09 \times \sqrt{2 \times 9.81 \times 0.07}$ $\mathrm{b}=2,34 \mathrm{~m}$

Jadi, dari data debit kala ulang rencana yang diperoleh dari metode rasional dapat menghasilkan lebar ambang untuk $Q_{5}=1,47$ $\mathrm{m}^{3} /$ dtk dengan $\mathrm{b}=1,50 \mathrm{~m}$, untuk $\mathrm{Q}_{50}=2,31$ $\mathrm{m}^{3} /$ dtk dengan $\mathrm{b}=2,20 \mathrm{~m}$, dan untuk $\mathrm{Q}_{100}=$ $2,55 \mathrm{~m}^{3} / \mathrm{dtk}$ dengan $\mathrm{b}=2,34 \mathrm{~m}$. Hasil rekapitulasi perhitungan desain bangunan bagi dan bangunan sadap disajikan pada tabel Tabel 16 dan Tabel 17.

Tabel 16. Rekapitulasi Perhitungan

Bangunan Bagi dan

Bangunan Sadap

Berdasarkan Debit Saluran di Lapangan.

\begin{tabular}{|c|c|c|c|c|c|c|}
\hline Ruas & $\begin{array}{c}\text { Q } \\
\left(\mathrm{m}^{3} / \mathrm{dt}\right)\end{array}$ & $\mathrm{M}$ & $\begin{array}{c}\mathrm{h} \\
(\mathrm{m})\end{array}$ & $\begin{array}{c}\mathrm{g} \\
(\mathrm{m} / \mathrm{dt})\end{array}$ & $\begin{array}{c}\mathrm{z} \\
(\mathrm{m})\end{array}$ & $\begin{array}{c}\mathrm{B} \\
(\mathrm{m})\end{array}$ \\
\hline $\begin{array}{c}\text { BW. } \\
1\end{array}$ & 0,21 & 0,85 & 0,40 & 9,81 & 0,1 & 0,44 \\
\hline $\begin{array}{c}\text { BS } \\
2 \mathrm{~A}\end{array}$ & 0,06 & 0,85 & 0,25 & 9,81 & 0,07 & 0,24 \\
\hline
\end{tabular}

Tabel 17. Rekapitulasi Perhitungan

Bangunan Bagi dan

Bangunan Sadap

Berdasarkan Debit Kala

Ulang Rencana.

\begin{tabular}{|c|c|c|c|c|c|c|}
\hline Ruas & $\begin{array}{c}\mathrm{Q} \\
\left(\mathrm{m}^{3} / \mathrm{dt}\right)\end{array}$ & \begin{tabular}{|r|}
$\mathrm{H}$ \\
$(\mathrm{m})$
\end{tabular} & $\mathrm{M}$ & $\begin{array}{c}\mathrm{g} \\
(\mathrm{m} / \mathrm{dt})\end{array}$ & $\begin{array}{c}\mathrm{z} \\
(\mathrm{m})\end{array}$ & $\begin{array}{l}\text { B } \\
(\mathrm{m})\end{array}$ \\
\hline \multirow{3}{*}{$\begin{array}{c}\text { BW. } \\
1\end{array}$} & 2,22 & 1,05 & & \multirow{3}{*}{9,81} & \multirow{3}{*}{0,1} & 1,78 \\
\hline & 3,49 & 1,20 & 0,85 & & & 2,44 \\
\hline & 3,86 & 1,24 & & & & 2,60 \\
\hline \multirow{3}{*}{$\begin{array}{l}\mathrm{BS} \\
2 \mathrm{~A}\end{array}$} & 1,47 & 0,98 & \multirow{3}{*}{0,85} & \multirow{3}{*}{9,81} & \multirow{3}{*}{0,07} & 1,50 \\
\hline & 2,31 & 1,05 & & & & 2,20 \\
\hline & 2,55 & 1,09 & & & & 2,34 \\
\hline
\end{tabular}

\section{KESIMPULAN}

Kesimpulan yang dapat diambil dari penelitian ini melalui hasil perhitungan yang telah dilakukan yaitu dimensi saluran berdasarkan debit saluran dilapangan pada saluran sekunder BW.1 didapat nilai b (lebar dasar) sebesar 0,52 $\mathrm{m}$ dan nilai $\mathrm{h}$ (tinggi air) sebesar 0,52 $\mathrm{m}$ dan pada saluran tersier BS $2 \mathrm{~A}$ didapat $\mathrm{b}$ sebesar $0,35 \mathrm{~m}$ dan $\mathrm{h}$ sebesar 0,35 m. Dimensi ini lebih kecil dari dimensi pengukuran di lapangan yaitu pada saluran sekunder BW.1 dengan nilai b sebesar $1,1 \mathrm{~m}$ dan $\mathrm{h}$ sebesar $0,40 \mathrm{~m}$ dan pada saluran tersier BS 2A dengan nilai b sebesar $0,75 \mathrm{~m}$ dan $\mathrm{h}$ sebesar $0,25 \mathrm{~m}$ sehingga tidak perlu dilakukan pelebaran.

Hasil Perhitungan dimensi bangunan bagi dan bangunan sadap berdasarkan debit 
saluran di lapangan diperoleh nilai b(lebar bangunan) untuk BW.1 sebesar $0,44 \mathrm{~m}$, dimensi ini lebih besar dari dimensi dilapangan dengan nilai $\mathrm{b}$ sebesar $0,35 \mathrm{~m}$ sehingga perlu dilakukan pelebaran. Sedangkan untuk BS.2A diperoleh nilai $b$ sebesar $0.24 \mathrm{~m}$, dimensi ini lebih kecil dari dimensi dilapangan dengan nilai $b$ sebesar 0,60 $\mathrm{m}$ sehingga tidak perlu dilakukan pelebaran.

Hasil Perhitungan dimensi bangunan bagi dan bangunan sadap berdasarkan debit kala ulang diperoleh nilai $b$ untuk bagunan bagi BW.1 dengan $\mathrm{Q}_{5}$ sebesar $1,78 \mathrm{~m}, \mathrm{Q}_{50}$ sebesar 2,44 m, dan $Q_{100}$ sebesar 2,60 m. Bangunan sadap BS 2A dengan $Q_{5}$ sebesar $1,50 \mathrm{~m}, \mathrm{Q}_{50}$ sebesar $2,20 \mathrm{~m}$, dan $\mathrm{Q}_{100}$ sebesar 2,34 m. Dimensi dari hasil perhitungan ini lebih besar dari dimensi dilapangan sehingga perlu dilakukan pelebaran.

\section{DAFTAR PUSTAKA}

Bezzel, O., Fauzi, M., dan Besperi. 2017. Analisis Kehilangan Air pada Saluran
Primer di Desa Kemumu Bengkulu

Utara. Universitas Bengkulu, Bengkulu.

DPU.1986. Perencanaan Jaringan Irigasi

KP-01. Standar Perencanaan Irigasi, Departemen Pekerjaan Umum Direktorat Jenderal Pengairan. Penerbit PU, Jakarta.

Mawardi, E. 2010. Desain Hidraulik

Bangunan Irigasi. Alfabeta, Bandung.

Prawaka, F., Zakaria, A., dan Tugiono, S.

2016. Analisis Data Curah Hujan yang

Hilang dengan Menggunakan Metode

Normal Ratio, Inversed Square

Distance, dan Rata-Rata Aljabar.

JRSDD Vol. 4 No.3. Teknik Sipil

Universitas Lampung, Lampung.

Rahayu, A. S., Amri, K., dan Besperi. 2017.

Analisis Efisiensi Penyaluran Air

Irigasi Kawasan Kemumu Kabupaten

Bengkulu Utara. Tinjauan Saluran

Sekunder dan Saluran Tersier.

Universitas Bengkulu, Bengkulu.

Suripin, 2004. Sistem Drainase Yang

Berkelanjutan. Penerbit Andi Offset, Yogyakarta. 